\title{
Air quality in Mexico City during the fuel shortage of January 2019
}

\author{
Jorge Luis García-Franco \\ Atmospheric, Oceanic and Planetary Physics, Department of Physics, University of Oxford. Clarendon \\ Laboratory, Parks Road Oxford, Oxford, United Kingdom OX1 3PU email: \\ jorge.garcia-franco@physics.ox.ac.uk
}

\begin{abstract}
1 The closure of pipelines to tackle fuel-theft in central Mexico caused an unexpected fuel shortage that disrupted transport systems in Mexico City in January of 2019. Fuel sales in the Metropolitan Area and $C O$ emissions from reanalysis showed a significant decrease during the 4 fuel shortage of $7 \%$ and $6 \%$, respectively. This study analyses the air quality and meteoro5 logical conditions during this period to evaluate whether these measures indirectly affected 6 air quality in Mexico City. During the shortage, mean-ambient concentrations of nitric oxide 7 (NO), nitrogen dioxide $\left(\mathrm{NO}_{2}\right)$ and carbon monoxide $(C O)$ were significantly lower than normal 8 whereas levels of particulate matter (PM) were only modestly lower than usual. Daily-mean $9 \quad N O$ and $C O$ had record-low anomalies of $-10 \mathrm{ppb}$ and $-0.5 \mathrm{ppm}$ from typical days, respectively. 10 In contrast, ozone mean-levels were not significantly different than average. The percentage 11 of days with PM mean concentrations above the World Health Organisation guidelines (5 and $1219 \%$ for particles smaller than 2.5 and $10 \mu \mathrm{m}$, respectively) and the percentage of ozone 8-h 13 rolling means above Mexican law (0.5\%) were record lows. Meteorological factors, such as wind 14 speed or the mixed-layer height were not significantly different than average. The anomalously low pollution levels were accentuated when each day was compared to days of similar flow patterns. This episode of better than usual air quality showcases how strategies addressing transport emissions could control air quality in Mexico City and highlights that improving ozone mean levels require comprehensive strategies that reduce emissions from all sectors.
\end{abstract}

Keywords: Air pollution, Meteorological forcing, Ozone, Primary pollutants, Transport emissions

\section{Introduction}

A fuel theft crisis forced Mexican authorities to close the pipelines that transport fuel in central Mexico causing a shortage of gas in Mexico City that started in early January 2019 
(McDonnell, 2019, Angulo, 2019, Specia, 2019). The unexpected shortage of gasoline and diesel affected economic activities and the transport sector in the megacity for at least two weeks (McDonnell, 2019). In January 2019, national petrol sales decreased by $2.7 \times 10^{4} \mathrm{~m}^{3}$ and diesel sales by $4.8 \times 10^{4} \mathrm{~m}^{3}$, which represent a reduction of $4 \%$ for petrol and $14 \%$ for diesel from normal levels. Specifically in Mexico City, one station reported sales decreasing by almost $12 \%$ whereas the mean of all the sub-stations in the Metropolitan Area showed sales decreased by $7 \%$. Furthermore, the daily mean number of passengers on public transport (bus service and underground/subway) increased significantly. The subway saw more than $1.4 \times 10^{5}$ more passengers per day $(+4 \%$ increase $)$ than in the last five years during the two week window of Jan. 8-26 2019, a period where the fuel shortage had the most dramatic effect. Similarly, the overground service had more than $7.0 \times 10^{4}$ passengers per day above average levels during the same period, which represents a $30 \%$ increase from previous years. In two cameras stationed in cycling routes, 1000 and 200 more cyclists per day than usual were spotted, which is approximately 49 and $21 \%$ above normal, respectively. The primary purpose of this study is then to document and quantify the changes to air pollution levels during the fuel shortage to better understand the potential impact of current and future air quality strategies in major Mexican urban-centres.

Air pollution is an outstanding public health issues (Bell and Davis, 2001, Holgate, 2017), particularly in megacities such as Mexico City (Baklanov et al., 2016, WHO, 2016). Pollution levels in Mexico City improved after alarming levels of ozone encouraged several air quality strategies in the 1990s (Molina et al., 2010). However, current levels of particulate matter (PM) and ozone are still frequently above the guidelines of the World Health Organisation (WHO) (WHO, 2016, Velasco and Retama, 2017). The health burden attributed to PM in central Mexico has increased in recent decades (Butt et al., 2017) due to the known cardiovascular and cerebrovascular effects of PM (Anderson et al., 2012). Even more concerning is the fact that monthly-mean values of PM in the winter season are above the 24-h mean limit of the WHO (SEDEMA-CDMX, 2018a, WHO, 2019) (see Figure 1).

The transport sector is the main source of primary pollutants in Mexico City (SEDEMACDMX, 2018b). For that reason, air quality strategies have aimed to reduce transport emissions, for example through the program known as "Hoy No Circula" (HNC) which bans cars based on their emission levels and license plates. The HNC program began banning cars based on the age of vehicles, but nowadays, the program is based on a test that measures vehicle emissions of carbon monoxide $(C O)$ and nitrogen oxides $\left(N O_{x}\right)$. The least polluting vehicles 
can transit freely whereas the most polluting category of vehicles are banned one weekday and every Saturday from 5 am to $11 \mathrm{pm}$. A middle category is banned one weekday per week but only one Saturday a month. For more detail on historical and current regulations of the HNC, see Molina et al. (2019). The HNC was found to be statistically ineffective on air pollution levels (Davis, 2008), even when recently extended to include Saturdays (Davis, 2017). Several factors account for the inefficacy of this driving restriction program. One explanation is that corruption at the facilities that measure vehicle emissions has allowed polluting vehicles to avoid the ban (Oliva, 2015). Other studies argued (e.g. Davis, 2008, Gallego et al., 2013) that households with a banned car have purchased a second vehicle to maintain driving habits, thereby keeping constant the number of vehicles in traffic. Alternatively, Guerra and MillardBall (2017) suggested that households adapted to the program by effectively scheduling their mobility according to the ban schedules.

Meteorological forcing can affect the daily and seasonal evolution of pollutants through an interplay of physical and chemical processes (Seinfeld and Pandis, 2016). For instance, synoptic-scale weather patterns significantly influence daily variability in ambient concentrations through the modulation of, e.g., local circulations, cloud cover and vertical mixing (e.g Zhou et al., 2018, Pozo et al., 2019). Other meteorological factors such as stratospheric ozone intrusions can inject ozone in the Mexico Basin increasing ozone levels in Mexico City (Barrett et al., 2019). In particular, de Foy et al. (2005) found that three distinct synoptic patterns influence air pollution levels in Mexico City during the warm dry season (Mar-Apr) by coupling to the local wind patterns or by changing the stability conditions. Furthermore, de Foy et al. (2008) found that the surface winds can be clustered into flow patterns that are associated with drainage and venting of the Basin.

The fuel shortage occurred during the cold dry season when synoptic forcing creates an environment suitable for temperature inversions in the Mexico Basin inhibiting vertical mixing which can lead to poor air quality episodes (SEDEMA-CDMX, 2018a). Nevertheless, typical radiative warming, even in winter, is significant and enables strong vertical mixing during the daytime that normally deepens the mixed-layer (Whiteman et al., 2000, García-Franco et al., 2018). In short, the coupling of local and regional circulations largely control the daily variability of pollution levels in Mexico City. Given that meteorological forcing plays an important role in air quality, any episode with extremely low or high pollution levels must be analysed and compared with episodes of similar meteorological forcing.

This paper examines ambient concentrations observed in the Mexico City Metropolitan 
Area (MCMA) during the shortage of fuel in the city indirectly caused by the measures to tackle fuel-theft. The main purpose is to document how pollution levels changed as a result of low fuel sales and increased public transport passengers. The remainder of this paper is organised as follows. Section 2 describes the data and methodology used to analyse air quality and meteorological data. Section 3 documents the air quality observed during the shortage of fuel. Section 4 highlights the meteorological conditions during the period of fuel shortage as well as the changes in aerosol content. Finally, section 5 provides a summary and discussion.

\section{Data and methodology}

This section describes the multiple data sources as well as the methods used for analysis. Monthly-mean national and regional gasoline and diesel sales were downloaded from "Petróleos Mexicanos" (PEMEX) available at http://www.pemex.com/ri/Publicaciones/. The daily counts of cyclists in two of the main cycling routes were downloaded from https: //datos.cdmx.gob.mx/, provided by the Agencia Digital de Innovación Pública (ADIP) for the routes labelled "Patriotismo" and "Reforma 222". The monthly-mean number of passengers on board the bus service ("Red de Transporte de Pasajeros-RTP") and the daily-mean number of passengers underground service ("Sistema de Transporte Colectivo-Metro") were retrieved through a request to the National Institute for Transparency of Mexico City. These datasets were, first, linearly detrended, and then, the January value of 2019 of the monthlymean datasets (i.e. the gas sales and RTP passengers) was compared to the January mean value of the entire dataset to report the anomalies and percentages of the previous section. The daily-mean datasets followed an identical procedure but the comparison was restricted to the period of Jan. 8-26 as this showed the greatest anomalies in all three datasets (cycling routes and subway data).

Media reports place the start of the fuel shortage around the 8th of January but the date of return to "normal" activities is not clear. However, results in section 3 will highlight that the fuel shortage was perceivable in ambient concentrations from January 8th until January 26th, 2019 and this period agrees well with positive ciclying and subway user anomalies. Air quality and meteorological conditions analyses were analysed during this two-week window, hereafter the fuel shortage period. 


\subsection{Air quality data and analysis technique}

Hourly ambient concentrations were downloaded from the Automated Atmospheric Monitoring Network (Red Automática de Monitoreo Atmosférico - RAMA) available at http: //www.aire.cdmx.gob.mx/. The pollutants considered in this study are nitric oxide NO, nitrogen dioxide $\mathrm{NO}_{2}$, ozone $\left(\mathrm{O}_{3}\right)$, carbon monoxide $(\mathrm{CO})$ and particulate matter smaller than $2.5 \mu m\left(\mathrm{PM}_{2.5}\right)$ and $10 \mu m\left(\mathrm{PM}_{10}\right)$. During the fuel shortage, not all stations of the monitoring network were active; therefore, the results shown herein are only for concentrations measured by 19 stations active during the fuel shortage. Note that not all of these 19 stations measure all pollutants considered in this study. These stations have the following codes given by the Automated Network: 'ACO', 'AJM', 'ATI', 'CHO','CCA', 'CUA', 'CUT', 'FAC', 'HGM', 'IZT', 'MER', 'MGH', 'NEZ', 'SAG', 'SFE', 'TLA', 'UIZ' y 'XAL'. For a spatial location of these stations, see Figure 1 of Retama et al. (2015) or at the RAMA site.

Air quality data was analysed via the comparison of a long-term sample with the 2019 sample, in the Jan. 8-26 window only. Moreover, to better understand the relative change in concentrations during the fuel shortage, the weekly and seasonal cycle must be taken into account (Stephens et al., 2008, Molina et al., 2010, Retama et al., 2015). For this reason, the weekly and monthly signal was removed from the daily-time series of each pollutant at each station. The mean value of a typical weekday of a given month was subtracted from each daily mean concentration resulting in an anomaly value. For example, for each Monday in the time-series, the anomaly value is the daily-mean value of that Monday minus the mean value for all Mondays on record in that month.

Carbon monoxide emissions were obtained from the Modern-Era Retrospective analysis for Research and Applications, Version 2 (MERRA-2), which is produced by NASA's Global Modeling and Assimilation Office. MERRA-2 assimilates satellite information about ozone, aerosol optical depth, total column carbon monoxide, as well as forest fire and volcanic emissions to then provide gridded analyses of $C O$, ozone and $\mathrm{NO}_{2}$, as well as emissions of $C O$ (Gelaro et al., 2017). The emissions were only considered during the peak rush-hour (15-21 h GMT), since MERRA-2 emissions are generally constant in the rest of the hours of the day.

\subsection{Meteorological data and analysis technique}

The Automated Monitoring Network provides wind and temperature hourly mean observations at each station. Radiosonde observations were available twice a day (at 6 and 18-h local time) taken at Tacubaya, Mexico City, downloaded from the University of Wyoming: 
http://weather.uwyo.edu/upperair/. A low-cost Lidar system, a ceilometer Vaisala CL31 (Münkel et al., 2007), has been measuring backscattering signals at a station from the Air Quality Monitoring Network (labelled 'CCA') since 2009. This ceilometer is part of the University Network of Atmospheric Observatories (RUOA) handled by the Centre for Atmospheric Sciences independently from RAMA. Ceilometer data provide processed backscattering profiles at $10 \mathrm{~min}$ and 10-m temporal and spatial resolution. The data is available upon request at https://www.ruoa. unam.mx/. The backscattering signal from the ceilometer is useful for air quality purposes since the signal is a well-known proxy of aerosol content given the scattering properties of aerosols (Münkel et al., 2007). Further use to the ceilometer data includes the computation of the mixed-layer height $(\mathrm{MLH})$, a very important air quality parameter (Doran et al., 1998, Molina et al., 2010). The MLH is determined as in García-Franco et al. (2018) using the covariant wavelet transform method.

The reanalysis data is from the latest reanalysis product of the European Centre for Medium-Range Weather Forecasts (ECMWF): ERA-5 (C3S, 2017). Surface variables such as temperature at $2-\mathrm{m}(t 2)$ and mean sea-level pressure (mslp) were used at a $0.25^{\circ} \times 0.25^{\circ}$ resolution whereas geopotential height at $500 \mathrm{hPa}$ (GPH500), outgoing long-wave radiation (OLR) and wind speed at 500 and $850 \mathrm{hPa}$ were used at a $0.75^{\circ} \times 0.75^{\circ}$ resolution. Multivariate empirical orthogonal function $(\mathrm{EOF})$ or principal component analysis (PCA) (Wilks, 2011 ) is a standard technique to find large-scale patterns that represent the variability of meteorological fields (see e.g. Seastrand et al., 2015). The multivariate PCA analysis was done for daily GPH500 and OLR fields, since these fields account for circulation in the mid-troposphere, and are a good proxy of surface temperature and cloud cover. The skill of the PCA analysis in influencing surface meteorological and air quality conditions is shown in section 4.1. This analysis was done in the period 2000-2019, only during the month of January, as the patterns of variability may be different in other seasons (Pozo et al., 2019).

\section{Air quality analysis}

This section analysis the ambient concentrations during the fuel shortage and compares them with the most recent record of observations. Throughout this and the following sections, concentrations are analysed and compared in the period of Jan. 8-26 only.

The time series of monthly and yearly-mean concentrations, Figure 1, shows the long-term behaviour and the seasonal cycles. Monthly-mean levels of ozone and particulate matter have remained stagnant over the last ten years, although this figure obscures changes in extreme 
levels (Rodríguez et al., 2016). In contrast, $C O$ and $N O$ levels show a decreasing trend. The monthly-mean values of $\mathrm{NO}, \mathrm{NO}_{2}$ and $\mathrm{CO}$ of January 2019 were a record-low for that month. However, these lower-than-normal concentrations of $C O$ and $N O$ could merely be a consequence of the long-term trends. The monthly-mean values of ozone and particulate matter during January 2019 were within the observed variability of recent years.

\subsection{Daily and weekly cycles}

The daily cycle of hourly-mean concentrations is controlled by the interplay of emissions, meteorology and chemistry depending on the hour of the day (Molina and Molina, 2002). Both the daily and weekly cycles cycle were constructed by first using regression analysis on monthly scales to measure the long-term trend, then the regression coefficients were interpolated to a daily time-series which was then used to regress out the long-term signal for each pollutant. For the case of daily cycles, the regression analysis was done for each hour of the day separately. This procedure makes the comparison between the fuel shortage period and the long-term mean straightforward.

The daily cycle during the fuel shortage (2019) was compared with the mean cycle of recent years (Figure 2). Due to the small sample size that composes the daily mean cycle of 2019, a bootstrap with replacement algorithm (1000 iterations) was used to provide a measure of uncertainty to the 2019 daily cycle for each pollutant. On average, the hourly means of daily cycle of 2019 were below the mean cycle of recent years, except for ozone (Figure 2). In fact, the daily ozone cycle of 2019 was almost identical to the mean cycle of recent years. The hourly means of particulate matter $\left(P M_{2.5}\right.$ and $\left.P M_{10}\right), N O_{x}$ and $C O$ were significantly lower during 2019 (from $\sim 10-15 \%$ up to $40 \%$ ) than the hourly means of the previous years. In most cases, except for ozone, the range of uncertainty in 2019 is frequently below the first quantile line of the long term sample. In other words, the hourly-mean levels of 2019 were anomalously, and these levels were not cause by the effect of the long-term trend.

The weekly cycles are shown in Figure 3, which illustrate how the mean-daily concentrations varied during the week confirming below average mean values. The mean weekday values were similarly below normal during the fuel shortage for all pollutants except ozone. While the decrease in concentration for, e.g., $\mathrm{CO}$ and $\mathrm{NO}_{2}$ can be observed in each day of the week, the sharp reduction during Sundays is noteworthy for all pollutants. $P M$ and $N O$ were mostly below normal levels as well for most days, although within the first quantile range in some days. The ozone weekend effect is similar to previous years, i.e., the sharp increase in ozone 
concentration during Sundays was of the same magnitude in 2019 than in last years.

A Welch two-sided t-test was performed between the January episode of 2019 and the long-term samples to characterise the significance of the differences in the daily and weekly cycles between 2019 and previous years. Although caution is warranted when establishing statistical significance with small sample sizes, the test showed $99 \%$ significant differences for all pollutants for the majority of hours and days of the week ( $>90 \%$ of hours and weekdays were significantly different), except ozone. In other words, the typical values were lower than usual for most pollutants, but the ozone daily and weekly cycles remained unchanged.

\subsection{Analysis of pollution levels without weekly cycle}

This section presents the daily-mean values with the weekly cycle removed, hereafter referred to as the anomaly values $(\bar{A})$. First, the linear long-term trend was removed as in previous sections. Then, the anomalies were computed for each day as the difference from the mean value for that day of the week during that month, in this case, January. This approach removes the effect of the long-term trend, the seasonal cycle and the weekly cycle. The daily anomalies at each station were separated into different distributions, a long-term sample, 2018only and 2019-only. Probability density functions (PDFs) summarise these distributions by illustrating the mean and spread of the different sub-samples (Figure 4). The PDFs of 2019 illustrate how close were the observations during the fuel shortage to typical or average values and to the PDF of 2018. The mean values of the long-term distribution (2000-2018) are close to zero, and the distributions are symmetrically distributed around the anomaly-zero value, as constructed. However, the mean $\bar{A}$ of the 2019 sample are different in both mean and spread with significantly asymmetrical PDFs to the zero anomaly value.

First, consider the PDFs of particulate matter, both $P M_{10}$ and $P M_{2.5}$. While the mean values of 2019 are not far from the 2000-2018 mean, the right-hand tail of the distributions of observations from 2019 is cut-off at $\sim 20 \mu \mathrm{g} \mathrm{m}^{-3}$ (for both $P M_{2.5}$ and $P M_{10}$ ) which suggests that days with high levels of particulate matter were unusual during the fuel shortage. Secondly, the PDFs of $N O_{x}$ and $C O$ of 2019 when compared to 2000-2018 both suggest a significant decrease in the mean anomalies as well as a decrease in the frequency of higher than average values, i.e., less frequent positive anomalies. The highest probability of ozone anomaly values in the 2019 PDF is centred at zero with a smaller frequency of positive anomalies than in the 2000-2018 and 2018-only PDFs. In other words, ozone concentrations were more frequently "normal" than usual with less frequent extreme values (positive and negative). 
Each PDF at each year was tested via the Kolmogorov-Smirnov statistic (Wilks, 2011) with the long-term PDF (2000-2018). In other words, the distributions of both 2018-only and 2019-only were compared with the long-term PDF of 2000-2018 for each pollutant. The test showed that each one of the PDFs for each of the pollutants during 2019 was significantly different from the long-term PDF at the 99\% confidence level. Most years (not shown) showed no significance for any pollutants, which highlights the strength of decomposing the signal of its weekly and seasonal signals to analyse extreme pollution events. While some years did show significance, for example, 2010 for particulate matter, 2019 was the only year on record to have significantly different PDFs for all pollutants. The significance of the ozone PDF is explained by the frequency of extreme values, i.e., while the mean of the distribution was similar, the extreme values were less frequent than usual, producing substantial (and significant) differences in the PDFs.

A comparison of the mean and spread of the anomalies between 2019 and previous years is shown as a time-series of the mean and standard deviation of the anomaly values for each year (Figure 5). This figure illustrates how the mean anomaly values and variability of 2019 compare to previous years. The mean anomaly values of 2019 broke anomaly-low records for three pollutants: $\mathrm{CO}, \mathrm{NO}$ and $\mathrm{NO}_{2}$. $\mathrm{PM}_{10}$ was only slightly below-normal compared to other years that had stronger decreases (e.g. 2010), while $P M 2.5$ and $O_{3}$ had mean anomaly values very close to zero. Table 1 summarises these results by presenting the daily mean and standard deviations of ambient concentrations, as well as the mean and standard deviation of the daily anomaly values. This table highlights that: 1) the mean levels and anomalies of ozone were not different from previous years, 2) the slight decrease in mean levels of particulate matter and 3) the significantly large decreases in the mean levels of $N O_{x}$ and $C O$. The results of a Welch t-test, done on the anomaly samples for each pollutant, are also reported in Table 1. Significant decreases were found for all pollutants, except ozone which had no significant changes and had a mean anomaly value of zero, consistent with the results mentioned above.

\subsection{Frequency of poor air quality according of WHO guidelines}

Subsequently, to contextualise air quality during the fuel shortage in terms of health exposure, the frequency of days and hours above-permitted standards was measured for ozone and particulate matter. In both cases, this frequency is measured by a ratio $(R)$ defined as the ratio of the number of days/hours above the threshold guideline to the total number of days/hours in a given period. The ratios were computed first at each station (selecting only 
Table 1: Arithmetic daily mean and one standard deviation (std) concentrations in the 2005-2019 period, compared with 2019 only, as well as the mean anomaly $\bar{A}$ and (standard deviations) for the two periods (05-19) and 2019. The p-value reports the significance of a Welch t-test done on the 05-19 and 2019-only anomaly samples.

\begin{tabular}{c|c|c|c|c|c} 
Pollutant (units) & 05-19 mean (std) & 2019 mean (std) & $05-19 \bar{A}(\mathrm{std})$ & $2019 \bar{A}(\mathrm{std})$ & $\mathrm{p}$-value \\
\hline \hline$P M_{10}\left(\mu \mathrm{g} \mathrm{m}^{-3}\right)$ & $62.44( \pm 25.9)$ & $47.56( \pm 17.7)$ & $0.99( \pm 20.7)$ & $-9.50( \pm 12.1)$ & $<0.01$ \\
$P M_{2.5}\left(\mu \mathrm{gm}^{-3}\right)$ & $29.19( \pm 11.3)$ & $24.2( \pm 7.0)$ & $0.15( \pm 10.5)$ & $-4.51( \pm 6.5)$ & $<0.01$ \\
$O_{3}(\mathrm{ppb})$ & $24.63( \pm 9.2)$ & $24.78( \pm 5.6)$ & $0.06( \pm 8.1)$ & $-0.57( \pm 5.55)$ & $>0.05$ \\
$C O(\mathrm{ppm})$ & $1.142( \pm 0.52)$ & $0.486( \pm 0.20)$ & $0.045( \pm 0.43)$ & $-0.48( \pm 0.27)$ & $<0.01$ \\
$N O(\mathrm{ppb})$ & $35.35( \pm 22.6)$ & $19.94( \pm 14.5)$ & $0.98( \pm 16.3)$ & $-9.88( \pm 11.7)$ & $<0.01$ \\
$N O_{2}(\mathrm{ppb})$ & $34.7( \pm 11.6)$ & $24.40( \pm 7.7)$ & $0.65( \pm 9.3)$ & $-7.38( \pm 7.5)$ & $<0.01$
\end{tabular}

the period of Jan 8-26-only) and then averaged between all stations to produce a mean ratio for each year.

The ratio of days with 24 -h means of particulate matter $\left(P M_{2.5}\right.$ and $\left.P M_{10}\right)$ above WHO thresholds (25 and $50 \mathrm{\mu gm}^{-3}$, respectively) is presented in Table 2 for each year from 2004 to 2019. The mean $R$ was 0.05 (5\% of days) and 0.19 (19\% of days) for $\mathrm{PM}_{2.5}$ and $\mathrm{PM}_{10}$, respectively. These ratios were the lowest on record (Table 2). This result is consistent with the PDFs, in Figure 4, which showed anomalously low frequency of positive PM anomalies.

The ratios of hourly ozone concentrations (8-h running mean) above Mexican (R1) and WHO (R2) guidelines, $70 \mathrm{ppb}$ and $100 \mathrm{\mu gm}^{-3}$, respectively, was analysed identically (Table 2). While 2019 was not a record-low per WHO standards (R2 values), the lowest ratio for Mexican thresholds (R1) of the last 15 years was that of $2019(\mathrm{R} 1=0.005)$.

This result implies that the number of days with poor air quality in the period of the fuel shortage was amongst the lowest on record. A bootstrap test (Wilks, 2011) measured whether these results are statistically significant. First, a large sample with all the ratios of days/hours above guideline-levels from all stations for all years was created for the three pollutants $\left(\mathrm{PM}_{10}\right.$, $\mathrm{PM}_{2.5}$ and $O_{3}$ ). The bootstrap test for a given year consists of sub-sampling the large sample by randomly picking ratios into a sample of the same size as the real sample of that year. For instance, if 13 stations reported ratios in 2014, 13 random ratios are drawn from the large sample to compute the mean-ratio of this sub-sample. This process was repeated 20000 times. The statistical significance of a given ratio of a given year is then the percentage of random mean-ratios that were found below the actual ratio of that year. For instance, Table 2 
Table 2: Ratios (R) of days above WHO and Mexican guidelines for $P M 2.5, P M_{10}$ and $O_{3}$ computed at each station and then averaged per year during the period Jan 8-26 only. The ratios of hours above the Mexican and WHO guidelines are labelled R1 and R2, respectively. The p-value represents the percentage of permuted ratios (at each station) out of 100 that were found below each ratio by bootstrapping ratios from different years (see text).

\begin{tabular}{c|c|c|c|c|c|c|c|c} 
Year & $\mathrm{R} \mathrm{PM}_{10}$ & $\mathrm{p}^{-v a l ~ \mathrm{PM}_{10}}$ & $\mathrm{R} \mathrm{PM}_{2.5}$ & $\mathrm{p}$-val $\mathrm{PM}_{2.5}$ & $\mathrm{R} 1 O_{3}$ & $\mathrm{p}$-val R1 & $\mathrm{R} 2 O_{3}$ & $\mathrm{p}$-val R2 \\
\hline \hline 2014 & 0.42 & 47.55 & 0.27 & 67.28 & 0.015 & 7.29 & 0.098 & 6.49 \\
2015 & 0.42 & 45.52 & 0.25 & 57.04 & 0.053 & 99.92 & 0.175 & 99.96 \\
2016 & 0.31 & 6.10 & 0.21 & 37.17 & 0.026 & 58.75 & 0.112 & 27.24 \\
2017 & 0.44 & 55.66 & 0.26 & 61.86 & 0.022 & 36.53 & 0.142 & 89.91 \\
2018 & 0.45 & 61.22 & 0.3 & 82.72 & 0.011 & 1.05 & 0.101 & 7.91 \\
2019 & 0.18 & 0.01 & 0.05 & 0.005 & 0.005 & 0.0025 & 0.104 & 10.66 \\
\hline
\end{tabular}

reports this percentage to be $0.01 \%$ for 2019 and $47 \%$ for 2014 . Therefore, the bootstrap test showed that the results of 2019 for all three pollutants were statistically significant to the $99 \%$ significance level, except for the WHO guidelines for ozone, which were not significant, even to the $10 \%$ level (see column p-val R2 in Table 2).

\subsection{Ozone during the fuel shortage}

The previous section documented anomalous distributions observed pollution levels during the fuel shortage. Ozone mean-levels were in the normal range in spite of significant decreases of $N O_{x}$. Given that information regarding Volatile Organic Compounds (VOCs) and hydroxil radicals was not available, determining whether conditions during the fuel shortage enhanced ozone production is not feasible. However, this section aims to understand whether ozone production was similar to that of a "weekend effect" but with a longer duration.

Figure 6 shows the daily cycle of $\mathrm{NO}_{2} / \mathrm{NO}$ and $\mathrm{CO} / \mathrm{NO}$ ratios for the period of the fuel shortage, the previous ten years and Sundays-only. Increased ratios of $\mathrm{NO}_{2} / \mathrm{NO}$ during the fuel shortage suggest a different photochemical production of ozone in 2019, particularly in the late afternoon period. These higher-than-normal ratios observed in 2019 are similar to those typically seen during Sundays. The $C O / N O$ levels during the fuel shortage were lower than the long-term mean and the Sunday-mean levels. Since both $C O$ and $N O$ are mostly emitted by vehicles, the $C O / N O$ ratios, the difference between the fuel shortage ratios and the long-term mean reinforce the notion that ambient concentrations consistently show a response decreased vehicle emissions. However, the fact 2019 was much lower than Sunday ratios would 
suggest that primary emissions and chemistry were not similar to the emissions and chemical interaction of the weekend effect.

The weekend effect is defined (for ozone) as:

$$
O_{3-W E}=O_{3-S}-O_{3-W D}
$$

where $O_{3-W E}$ is the ozone weekend effect, $O_{3-S}$ is the Sunday-mean ozone concentration and $O_{3-W D}$ is the mean concentration of all weekdays. Analogous definitions were used for the rest of the pollutants.

The weekend effect of primary pollutants $(\mathrm{NO}$ and $\mathrm{CO})$ and ozone were compared between the fuel shortage period and a long-term record. The weekend effects of 2019 were of similar magnitude to the typical January weekend effect, i.e., ozone increased $+4.5 \mathrm{ppb}$ and $N O$ and $C O$ decreased $-16 \mathrm{ppb}$ and $-0.21 \mathrm{ppm}$, respectively, during the fuel shortage. The mean (standard deviation) weekend effect of the last 10 years for $\mathrm{O}_{3}, \mathrm{CO}$ and $\mathrm{NO}$, respectively, were $2.7( \pm 2.69) \mathrm{ppb},-11.1( \pm 10.4) \mathrm{ppb}$ and $-0.17( \pm 0.25) \mathrm{ppm}$. While the weekend effect for all pollutants was greater than normal, the variability of the weekend effect for these pollutants on the long-term sample is high and the sample size of 2019 is small. Therefore, the weekend effect during the fuel shortage was relatively within normal ranges.

The scatter of the station-mean ratios of $\mathrm{CO} / \mathrm{NO}_{x}, \mathrm{NO} / \mathrm{NO}_{2}, \mathrm{NO}, \mathrm{CO}$ and ozone are shown in Figure 7 . These mean values/ratios were computed during the daytime $(8-19 \mathrm{~h})$ in the Jan 8-26 window for three different periods: the fuel shortage period (2019-only), 20092018 and during Sundays. The low values of $C O$ during the fuel shortage are of relatively similar magnitude to Sunday values. However, NO daytime levels in 2019 were higher than during typical Sundays. Ozone mean concentrations during 2019 were relatively lower than Sunday mean values but well within the variability shown by the scatter of the 2009-2018 sample. However, precursor ratios of $\mathrm{CO} / \mathrm{NO}_{x}\left(\mathrm{NO} / \mathrm{NO}_{2}\right)$ are lower (higher) than Sundays and 2009-2018. In other words, either as a result of the long-term decrease in $N O$ and $C O$ or an effect of the decreased emissions during the fuel shortage, 2019 had anomalous daytime ratios of ozone precursors but average ozone concentration values.

\section{Meteorological influence}

This section analyses the meteorological conditions during the fuel shortage to address whether the anomalous low levels of pollution presented in the previous section were caused 
by meteorological forcing. First, the leading modes of synoptic variability in January are used to separate each day into distinct flow pattern categories or events. Surface wind speed and temperature are then analysed using the observations from the air quality monitoring stations. Then, the upper-level state of the atmosphere is documented using radiosonde data. Finally, ceilometer data was used to analyse aerosol and MLH behaviour.

\subsection{PCA patterns}

Figures 8a, b show the January mean surface temperature, wind (850-hPa) and GPH500 for the period 2000-2018. In turn, Figures 8c, d show the anomaly of these fields during January 2019 from this long-term mean. During the fuel shortage, surface temperatures across central Mexico were slightly above normal, but wind speed $\left(<1 \mathrm{~m} \mathrm{~s}^{-1}\right)$ and GPH500 $(15 \mathrm{~m})$ differences in Central Mexico were minimal. The dominant features in Figure 8c are the positive GPH500 anomaly in northwestern Mexico and a northerly wind anomaly in the Gulf of Mexico.

Although the mean meteorological conditions during the fuel shortage were not significantly different from normal, an anomalous frequency of certain flow patterns could have influenced air quality (de Foy et al., 2005, de Foy et al., 2008). The results from the PCA were used: first, to evaluate whether these patterns are actually related to pollution levels and, then, to address whether the anomalies during the fuel shortage were a consequence of the prevailing weather patterns during this episode.

The leading five PCS explained $82 \%$ of the daily variability in OLR and GPH500 but to evaluate whether these PCS are actually relevant for pollution levels in Mexico City, regression analysis was used. Table 3 shows the regression coefficients of a multivariate linear regression between the PC time-series and each pollutant, as well as the coefficient of determination $\left(R^{2}\right)$ which represents the fraction of the variance in each pollutant explained by a linear combination of all the PCS. All pollutants had a significant non-zero regression coefficient with at least three PCS.

Moreover, each day in January in the 2000-2019 period was classified into an episode or event category. This classification was done normalised PC time-series. For example, days were classified as positive PC1 if the maximum PC value for that day was PC1 and this value was positive. Table 4 reports the mean anomaly values for four types of episode in the longterm sample and in 2019-only. The values are reported for positive PC1, PC2 and PC3 events and negative PC4 events which account for $12 \%, 13 \%, 12 \%$ and $8 \%$ of the total days in the time-series (600). These are the episodes associated with increased pollution levels (see Table 
Table 3: Regression coefficients between each pollutant and each PC and the coefficient of determination $\left(R^{2}\right)$. The PC time-series was normalised so the units of the coefficients are expressed in concentration change per principal component unit (p.c.u.), i.e., ppbp.c.u. ${ }^{-1}$ for $C O, N O, N O_{2}$ and $O_{3}$ and $\mu g m^{-3}$ p.c.u..$^{-1}$ for $P M_{2.5}$ and $P M_{10}$. The coefficients that are significant to the $95 \%$ confidence level are shown in bold.

\begin{tabular}{c|cccccc} 
Pollutant & PC1 & PC2 & PC3 & PC4 & PC5 & $\mathrm{R}^{2}$ \\
\hline$O_{3}$ & $\mathbf{2 . 0}$ & $\mathbf{1 . 1}$ & $\mathbf{2 . 0}$ & $\mathbf{- 1 . 7}$ & $\mathbf{- 0 . 4}$ & 0.31 \\
$\mathrm{PM}_{10}$ & $\mathbf{5 . 1 7}$ & $\mathbf{2 . 6}$ & $\mathbf{3 . 1}$ & $\mathbf{- 3 . 8}$ & $\mathbf{- 3 . 5}$ & 0.22 \\
$\mathrm{PM}_{2.5}$ & $\mathbf{3 . 3}$ & 0.4 & 0.2 & $\mathbf{- 0 . 9}$ & $\mathbf{- 0 . 6}$ & 0.14 \\
$N O$ & -0.2 & $\mathbf{2 . 3}$ & $\mathbf{3 . 4}$ & $\mathbf{- 1 . 9}$ & $\mathbf{- 3 . 2}$ & 0.15 \\
$N O_{2}$ & $\mathbf{2 . 5}$ & $\mathbf{1 . 5}$ & $\mathbf{1 . 0}$ & $\mathbf{- 1 . 3}$ & $\mathbf{- 1 . 9}$ & 0.19 \\
$C O$ & 11.0 & 7.6 & $\mathbf{9 8 . 7}$ & $\mathbf{- 4 4 . 5}$ & $\mathbf{- 8 8 . 4}$ & 0.14
\end{tabular}

3). For instance, the regression coefficient between $\mathrm{PM}_{10}$ and $\mathrm{PC} 1$ suggest increased $\mathrm{PM}_{10}$ during positive PC1 events. Indeed, Table 4 reports that the mean anomaly value for positive $\mathrm{PC} 1$ events is $+6.5 \mathrm{\mu g} \mathrm{m}^{-3}$. However, the anomaly for positive PC1 episodes during the fuel shortage was $-10.9 \mathrm{\mu g} \mathrm{m}^{-3}$. Surprisingly, the same is true for the rest of possible combinations, except those involving ozone. In other words, during the fuel shortage, pollutant concentrations of $C O, N O_{x}$ and $\mathrm{PM}$ were negative and below the mean anomaly values expected for each type of episode.

The patterns associated with the episodes discussed above are shown in Figure 9 as composites of surface conditions, OLR and GPH500. While the purpose of this paper is not to address the physical mechanisms underlying the effect of these forcing patterns on air quality, there are a few noticeable features. Positive PC1 is associated with a strong northerly flow on the eastern coast of Mexico, as well as a surface high-pressure system in Central Mexico, which in turn is observed at $500-\mathrm{hPa}$ as an anticyclone. This pattern matches the description of a flow pattern that de Foy et al. (2005) referred to as O3-South. This type of flow pattern may increase air pollution via the higher stability, decreased cloud cover and lower-than-normal horizontal wind speed caused by the anticyclone. The positive PC3 also resembles the O3-North episodes discussed in de Foy et al. (2005) and de Foy et al. (2008) whereas surprisingly, the negative PC3, fits the description of "Norte events" or Cold-Surges. The composite patterns of negative PC3 events (not shown) indicate significantly colder than normal temperatures, strong northerly flow and strong mslp gradients in eastern Mexico, all indicative of cold front forcing. A detailed description of each positive and negative pattern is omitted for brevity. 
Table 4: Mean anomaly $(\bar{A})$ for each pollutant during four different PC episodes (see text). Anomalies are shown for the long-term record $(\bar{A})$ and during 2019-only $(\bar{A} 19)$, i.e., during the fuel shortage.

\begin{tabular}{c|cccccccc} 
Pollutant & $\bar{A}-1$ & $\mathrm{~A} 19-1$ & $\bar{A}-2$ & $\mathrm{~A} 19-2$ & $\bar{A}-3$ & $\mathrm{~A} 19-3$ & $\bar{A}-4$ & $\mathrm{~A} 19-4$ \\
\hline $\mathrm{O}_{3}$ & 1.3 & 2.8 & 2.6 & -5.1 & 3.0 & 5.4 & 2.0 & 0.6 \\
$\mathrm{PM}_{10}$ & 6.5 & -10.9 & 1.1 & -11.0 & 3.6 & -10.3 & 7.2 & -16.0 \\
$\mathrm{PM}_{2.5}$ & 3.0 & -2.1 & 0.2 & -7.5 & 0.0 & -4.6 & 2.5 & -9.15 \\
$N O$ & 4.4 & -18.6 & 0.25 & -9.3 & 5.1 & -13.23 & 5.1 & -10.4 \\
$N O_{2}$ & 3.65 & -6.1 & 2.8 & -9.0 & 2.1 & -5.1 & 2.8 & -10.3 \\
$\mathrm{CO}$ & 63.9 & -612 & -9.5 & -557.7 & 180 & -569 & 92.2 & -542
\end{tabular}

Table 4 only reports anomalies for the patterns that are associated with increased pollution levels by the regression coefficients. The analysis was repeated (not shown) for those episodes with improved pollution levels and the same conclusion is found: the mean anomaly values were lower during the fuel shortage. In fact, for all pollutants except ozone, the mean anomaly values had a probability lower than 0.02 in the PDF of each of the 8 types of episode. Although this last remark must be taken with caution as these PDFs associated with each type of PC pattern have a significantly lower sample size than those shown in Figure 4.

\subsection{Surface station and radiosonde data analysis}

The mean surface temperature from surface station data during the fuel shortage was $13.14^{\circ} \mathrm{C}$ which was within the inter-annual variability. A standard two-sided t-test showed that the temperature distribution of 2019 was not significantly different from the recent record.

Wind speed magnitude, analysed at each one of the 19 stations, in 2019 was also within typical values. The average wind speed throughout the stations is below $2 \mathrm{~m} \mathrm{~s}^{-1}$ in the longterm mean as well as in 2019. A standard t-test done at each station confirmed that in 2019 the wind distributions (in magnitude and direction) were not significantly (90\% confidence level) different from the long-term record. Wind roses (not shown) at each station showed no appreciable differences in the direction of the typical circulation between 2019 and the long-term mean.

Radiosondes were analysed via the wind speed magnitude $(|U|)$ near the surface and in the mid-troposphere, i.e., at 700 and $500-\mathrm{hPa}$, and the mean temperature below $700-\mathrm{hPa}$, i.e., the low-level temperature (LLT). The average mean wind speed at $700-\mathrm{hPa}$ is generally low $<5 \mathrm{~m} \mathrm{~s}^{-1}$ and 2019 was no exception with a mean wind speed of $3.3 \mathrm{~m} \mathrm{~s}^{-1}$. Mean-wind 
speed at the mid-troposphere was stronger $\left(|U| 500-\mathrm{hPa} \sim 10 \mathrm{~ms}^{-1}\right)$ than at $700-\mathrm{hPa}$. The mid-troposphere wind in 2019 was very close to the 1995-2018 mean value, in fact, closer than 0.25 standard deviations. The LLT was similarly well within the standard variability of the 1995-2018 values. A t-test showed that wind speed and temperature were not significantly different in 2019 from 1995-2018 mean to a 95\% confidence level.

\subsection{Aerosol loading and $M L H$}

The ceilometer data further evidenced aerosol behaviour during the fuel shortage and showed whether the MLH behaviour in 2019 was different from typical values. Figure 10 shows the daily mean backscattering profile and daily MLH evolution for a) 2011-2019 and b) 2019-only for the Jan 8-26 period. The typical mean daily cycle in low-level backscattering is characterised by a maximum backscattering observed at the lowest level during $8-11 \mathrm{~h}$, the peak rush hour in Mexico City, therefore very likely linked to surface aerosol emissions. This low-level maximum in the morning hours is followed by increased backscattering at higher levels, reaching significant aerosol signals above 2000-m at 13-14 h due to convective mixing (Jauregui, 1988, Whiteman et al., 2000). Panel b) shows a very similar daily cycle but with a decreased low-level signal magnitude, particularly after 10-h. Panel c) illustrates the differences between the profiles of 2019 and the long-term mean. The afternoon/early night rush hour (18-21 h) shows significantly low anomalies at the lowest level. Negative anomalies are also observed during convective mixing hours (12-16 h) at upper layers and in the residual (upper) nocturnal layers. Panels a,b) show that the height of stable boundary layer during nighttime was $\approx 500$-m whereas the MLH reached $\approx 2500$-m at the peak of convective mixing , 13-15 h. The MLHs were therefore not significantly different in 2019, in fact, the mean MLH in 2019 was within the typical variability range García-Franco et al. (2018).

The total aerosol content (TAC), which is the integrated concentration of aerosols in the boundary layer, can be estimated by integrating the backscattering signal in the boundary layer, i.e.:

$$
T A C \sim \frac{1}{M L H} \int_{100}^{M L H} B(z) d z
$$

where $B(z)$ is the backscattering signal and $T A C$ is integrated from 100-m until the MLH. The lower limit, 100-m, was chosen due to the known artefacts in the lowest levels in the ceilometer. Figure 11a) compares the daily cycle of the TAC of 2019 with that of 2011-2019. The TAC in 2019 is significantly lower than the typical mean TAC for all times but most 
notably after the afternoon rush hour in Mexico City (20-24 h). This significant decrease in the nocturnal signal is also observed in figure 10c) as the strongest low-level negative anomaly. These results independently confirm the lower than average concentrations of most pollutants in the afternoon (Figure 2), especially for the particulate matter.

The daily sum of the TAC, computed at each day and averaged per year, is shown in Figure 11b) which indicates that 2019 was a below-average year in TAC, with consistent inter-annual variations to those of Figure 5. These independent results, from the ceilometer and the ambient concentrations of particulate matter, suggest that during the fuel shortage aerosol levels were low but not outside of inter-annual variability.

\section{Relationship between fuel sales, emissions and pollution levels}

The fuel shortage episode affected both economic and transport sectors, and thus inherently links fuels sales, emissions and pollution levels. The previous sections documented that, overall, air quality improved during the fuel shortage and this improvement could not be explained by a long-term trend or the effect of meteorological forcing. The specific effect and magnitude of fuel sales on emissions and concentrations is not straightforward to quantify, however.

The context of the anomalously low sales of diesel and gasoline can be best understood by considering the typical month-to-month variations in sales and comparing the sales during the fuel shortage with the longer record. For instance, diesel sales had not been as low as they were during the fuel shortage (Jan 2019) since January 2005. For gasoline, sales had not been as low as in Jan. 2019 since July 2006. Moreover, sales have increased since January 2019, certifying that January 2019 had the lowest fuel sales on the recent record. Moreover, the decrease in gasoline and diesel sales from December 2018 to January 2019 was amongst the highest (negative) month-to-month variations on record. In fact, the sudden decrease during the fuel shortage was within the $10 \%$ sharpest negative changes for gasoline and the second sharpest for diesel. Given that fuel sale information is only available on monthly-scales, the effect of the fuel shortage was hard to compare against other metrics, e.g., variation from weekdays to weekends.

In turn, $C O$ emissions from MERRA-2 showed a similar negative response to the fuel shortage. The emission rates from 9-13 h (UT-6) were analysed as with previous datasets, i.e., the data was first detrended (these emission rates showed a negative significant trend), and then analysed in the Jan. 8-26 window-only. The resulting emission rates of 2019 were compared with the long-term sample of 2009-2018. This analysis showed that the emission 
rates during the fuel shortage were lower than normal but not the lowest mean value on the recent record. However, the median and minimum daily emissions were record-low during the fuel shortage, i.e, the lowest emission rates were found during the fuel shortage. Overall, mean and median emissions during the fuel shortage decreased by 4 and $6 \%$, respectively, from typical levels. The distribution of emission rates in 2019 also had the lowest first quantile on record, which is further evidence that emissions in MERRA-2 were below normal. While these results do not come from observed emissions, MERRA-2 assimilates a large number of satellite observations, which means that these lower-than-normal statistics of the emission rates are evidence that emissions must have been reduced in order for the model to match the satellite-observed concentrations.

In short, there was a coherent response between sales, $C O$ emissions and concentrations during the fuel shortage observed as significant and, in some statistics, record-breaking reductions. However, a regression analysis showed that on the longer term there was no statistically significant linear relationship between fuel (gasoline) sales and $C O$ emissions, or between fuel sales and the surface concentrations. This could be due to the fact that on longer time-scales sales are driven by economic factors, $C O$ emissions in MERRA-2 depend on the observed largescale pollution from satellites and concentrations also depend on chemistry and meteorology.

\section{Summary and discussion}

Fuel theft in central Mexico was tackled by the closure of pipelines that transport fuel in January 2019. This strategy produced an unexpected and unusual gas shortage in Mexico City affecting the transport sector and thereby vehicle emissions. Even though direct traffic flow estimates were not available, several indirect metrics provided insight into the changes to the mega-city during this episode. The increase in cyclists and public transport users, in addition to anomalously low national and regional petrol sales, are evidence that traffic conditions during the fuel shortage were not typical. This study analysed pollution levels during the fuel shortage and compared them to the observed record of air quality.

The weekly and daily cycles were significantly lower than usual for $C O, N O_{x}, P M_{2.5}$ and $P M_{10}$, except ozone, which was within the average values. When the weekly and seasonal cycles were removed from the daily time series for each station, the mean anomalies of most pollutants during the fuel shortage were negative, except for ozone, particularly $N O$ and $C O$ which broke anomaly-low records. Moreover, the frequency of extreme positive values, associated with days with worst air quality than usual, was well below average for all pollutants, including ozone. 
For instance, the daily-mean levels of particulate matter, typically well above WHO standards, were within the guideline levels during the fuel shortage in 2019 in more than $80 \%$ of the days, the best percentage on record for January. Similarly, the ratio of ozone hourly means above Mexican standards was a record low.

The role of meteorological forcing was considered via the separation between specific flow patterns as revealed by the leading PCS of GPH and OLR. Previously documented (de Foy et al., 2005, de Foy et al., 2008) flow patterns such as strong northerly flow in the Gulf of Mexico, or O3-North, and Cold-Surges had significant influence over ambient concentrations. Even during days when the dominant flow patterns would suggest increased air pollution levels, anomalies of primary pollutants during the fuel shortage were negative and significantly lower than the mean values for each type of pattern. The analysis of surface, radiosonde and MLH data showed typical January conditions in 2019 , i.e., the weak low-level winds, the temperature and MLH were very close to the long-term mean. Backscattering from ceilometer data (Figure 10) suggested that the aerosol content was significantly lower during 2019 than in the previous record, especially during the afternoon at lower-levels. Decreased aerosol signal during the afternoon, independently confirms the results of the air quality analysis which showed (Table 1 and Figure 2) that mean PM was lower-than-normal, particularly in the afternoon.

The fact that air quality during the fuel shortage was better not only in the mean-level sense but also in the frequency of unhealthy days, or the extreme end of the distribution, has important consequences for health burden (Bell et al., 2006, Butt et al., 2017). While vehicle emissions are not the primary source of PM in Mexico City, the contribution of the transport sector to particle emissions can certainly be the difference between poor or regular air quality. This contribution from the transport sector may explain the observed changes to the frequency of poor air quality days of $P M$ during the fuel shortage. The significant reduction in the frequency of poor air quality days, both for particulate matter and ozone, may suggest that a strategy with similar reductions in vehicle emissions to the fuel shortage can result in having only $20 \%$ poor air quality days in January, instead of the typical $45 \%$.

In spite of the improved air quality levels in primary pollutants and a modest reduction in $\mathrm{PM}_{10}$, ozone mean levels were virtually unaffected during this episode. This result is likely a consequence of the complex photochemical production of ozone, which depends on other chemical species. While other sources of pollution are very relevant in Mexico City, the main air quality strategies, such as the HNC, are aimed at reducing transport emissions. Air quality strategies aiming to reduce mean ozone levels should give equal focus to the sectors that emit 
VOCs, for example. The challenges of policies tackling transport emissions is enhanced in Latin American countries that exhibit rapid motorization (Hidalgo and Huizenga, 2013). Moreover, the stricter version of the HNC, typically used during extreme ozone events, may have null or even the opposite effect, as shown by this study.

The lack of robust data on traffic flow is a shortcoming of this study. First, because no comparison could be made between the driving conditions of the fuel shortage and the HNC which might have helped to better elucidate the reasons why this program has remained ineffective. Similarly, this study could not determine any metric on traffic flow that could be directly related to the anomalies shown in this study, which could be most useful for policy-makers. The length of the fuel shortage episode was sufficiently long so that regional backgrounds may have been affected by a relatively cleaner than normal Mexico City Metropolitan Area. The changes to the background concentration of several species may have modified chemical reaction rates and the effect of transport on pollution levels. A regional chemistry model may provide further insight into the effect of the fuel shortage on regional pollution and air quality levels in Mexico City. Further analysis must be done to better characterise the influence of the traffic flow on the pollution levels shown in this study via mobility metrics that quantitatively represent the changes to traffic behaviour during this episode and compares them to a longer-term record. Observational and numerical analyses of the traffic flow would be most useful for air quality strategies, both to implement new versions of the HNC, but also to plan alternative strategies regarding the emission of other sectors.

\section{Acknowledgements}

JLGF was supported by CONACyT-SENER and Oxford-Richards Scholarships for Climate Studies at Wadham College. This study was possible due to the noteworthy efforts of the RAMA, RUOA, PEMEX, ADIP and Met Service staff for collecting and sharing their data as well as to ECMWF and NASA for sharing their reanalysis. The author would also like to thank three anonynomous reviewers for their comments which have greatly improved this manuscript and to Diego Alvarado and Karen Solorzano for helpful discussions. 

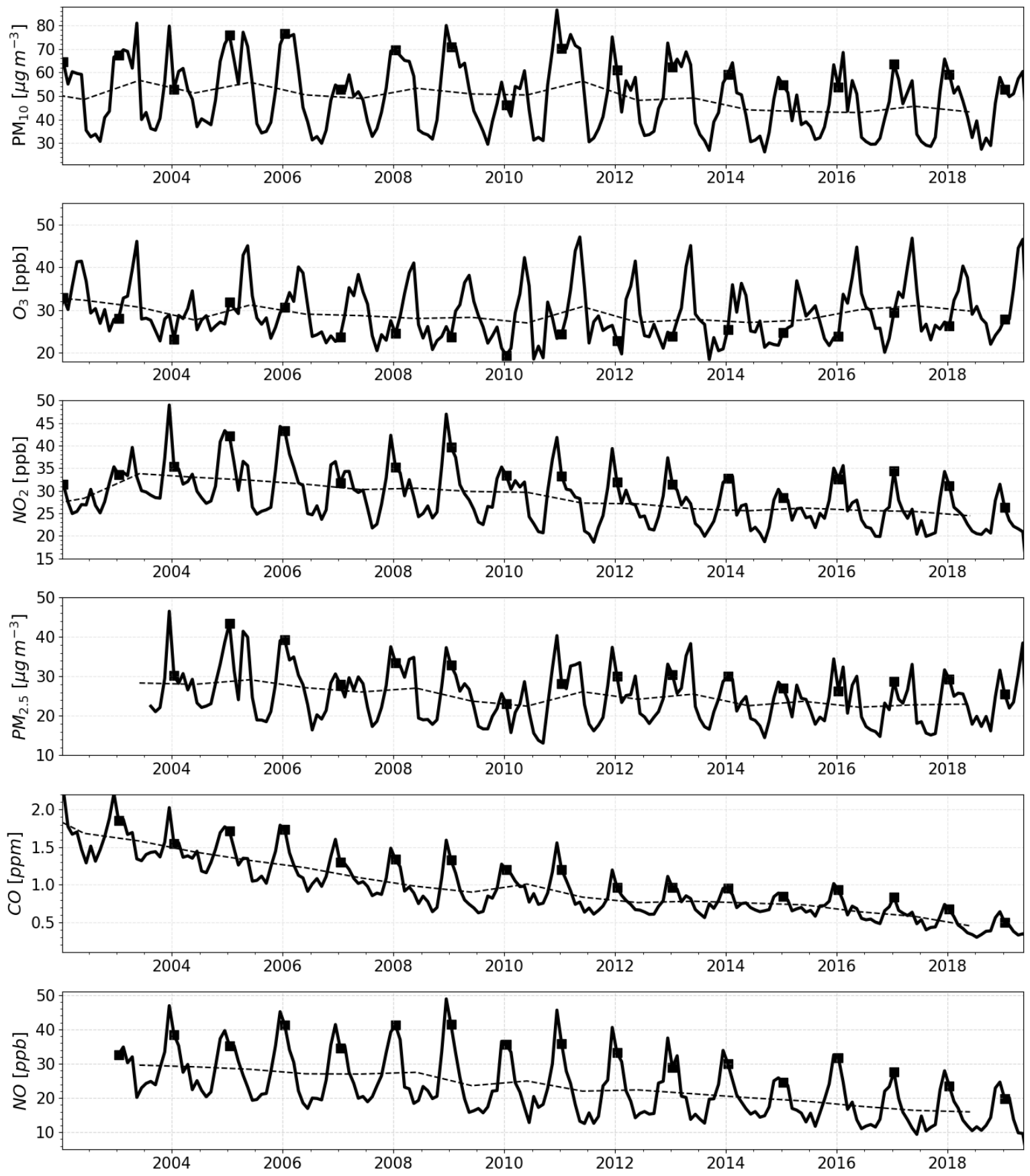

Figure 1: Time series of monthly (solid) and yearly (dashed) means for six pollutants as indicated in the y-labels using data from the 19 stations active during the fuel shortage. The squares indicate the January mean value. 

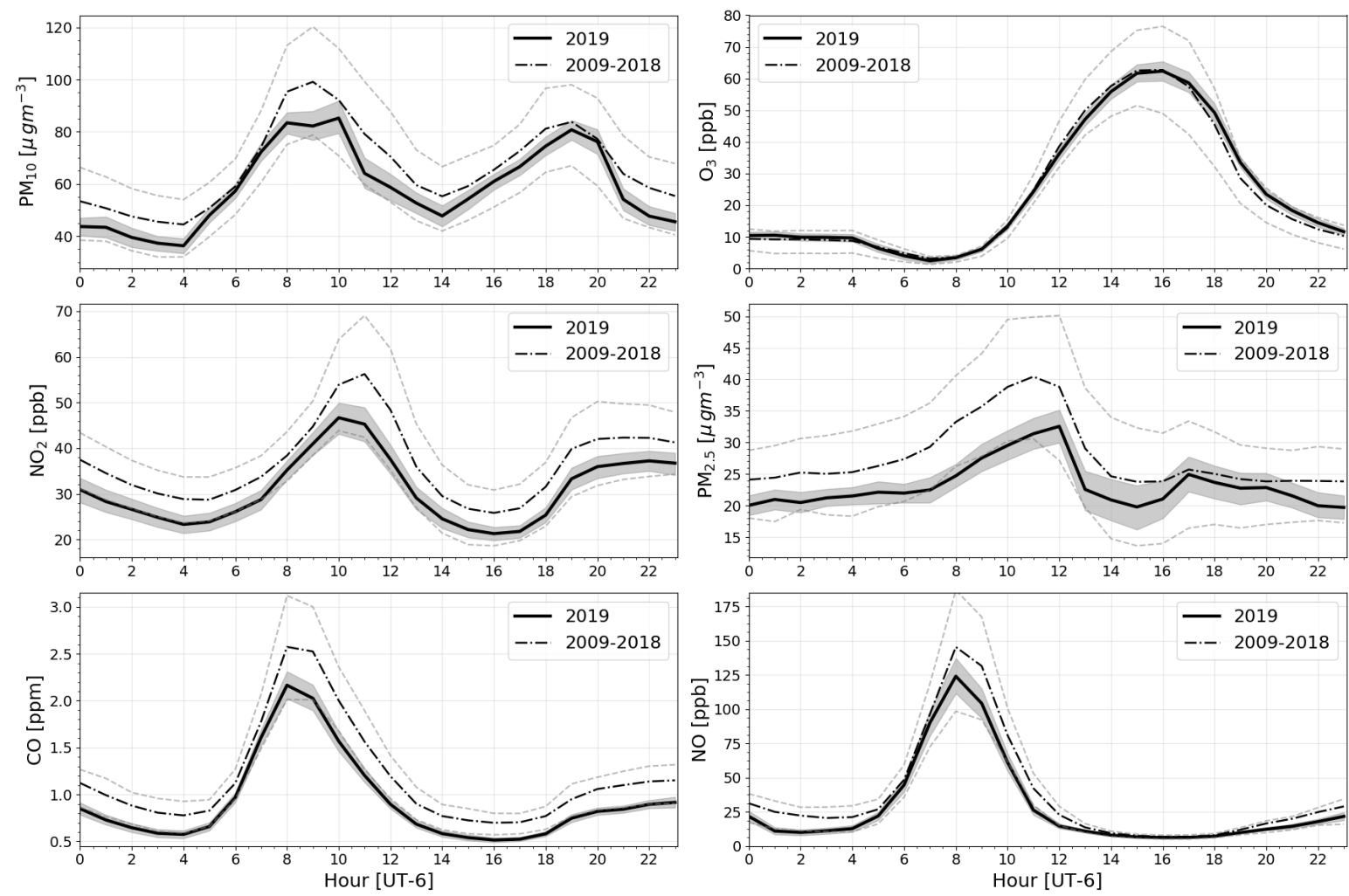

Figure 2: Daily cycle of hourly-mean-concentrations for the fuel shortage period in 2019 (solid) and the mean daily cycle of previous years (dashed) for six pollutants. The faint dashed grey lines indicate the 1st and 3rd quantiles of the long-term samples and the grey shading is a measure of uncertainty for the 2019 daily cycle as described in the text. 

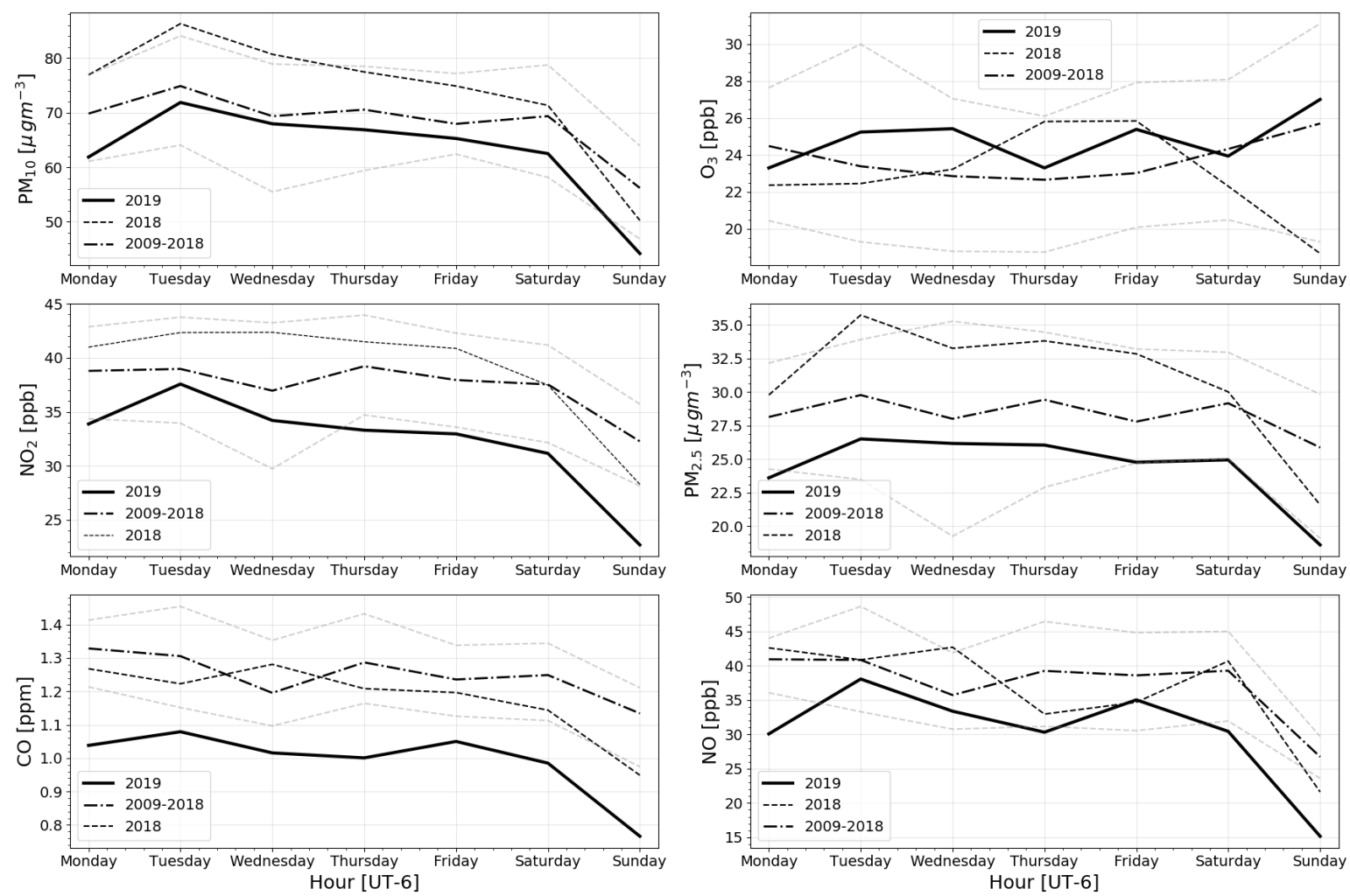

Figure 3: Weekly cycle of daily-mean concentrations during the fuel shortage in 2019 (solid), 2018 and a composite of previous years (dashed), as indicated in the legends. The faint gray lines show the first and third quantiles of the long-term distribution. 

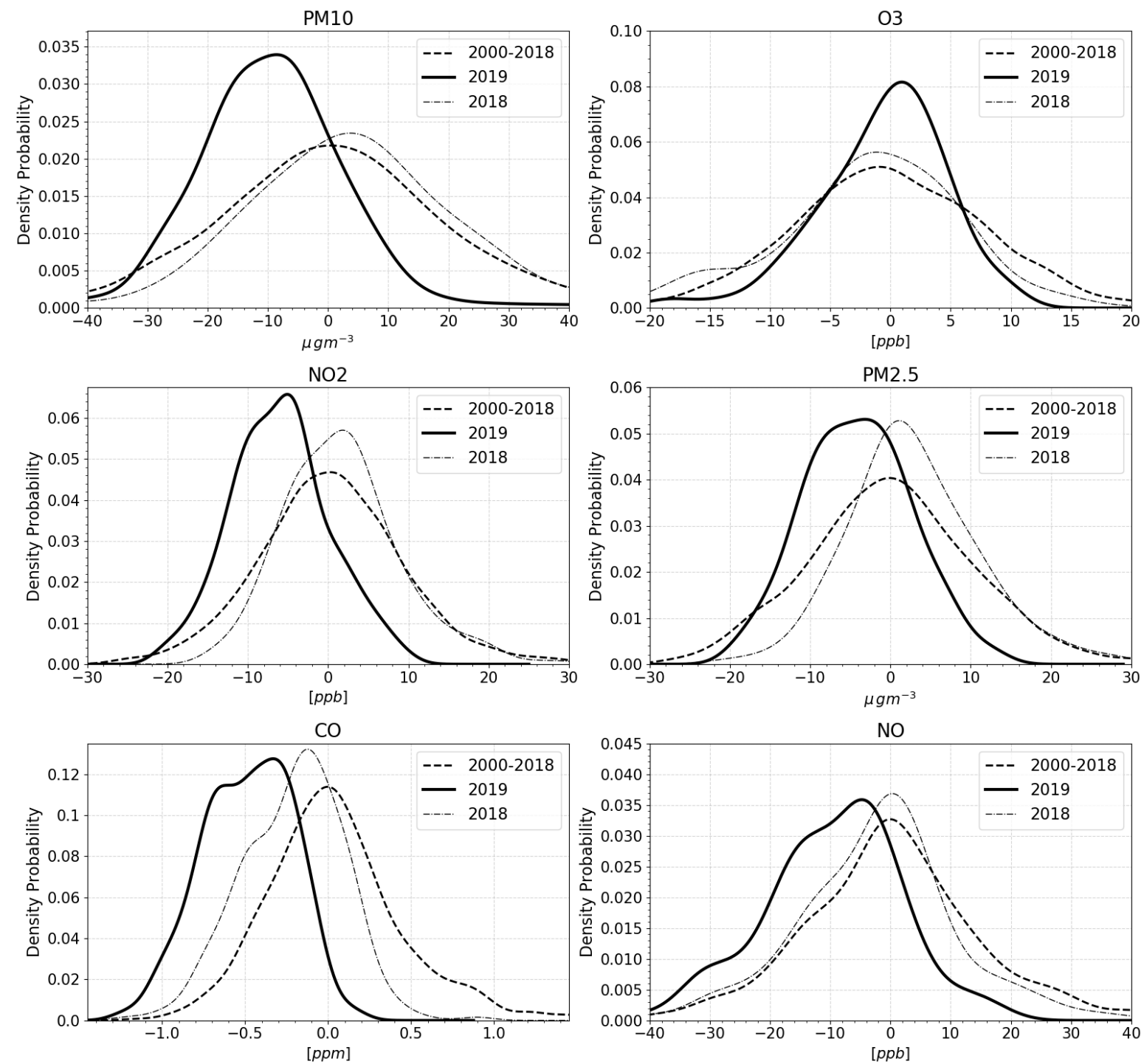

Figure 4: Probability density functions of the decomposed daily-mean anomaly values during the fuel shortage period (8-26 Jan) for 2019 (solid line), 2018 (faint dashed line) and the last 19 years (2000-2018). 

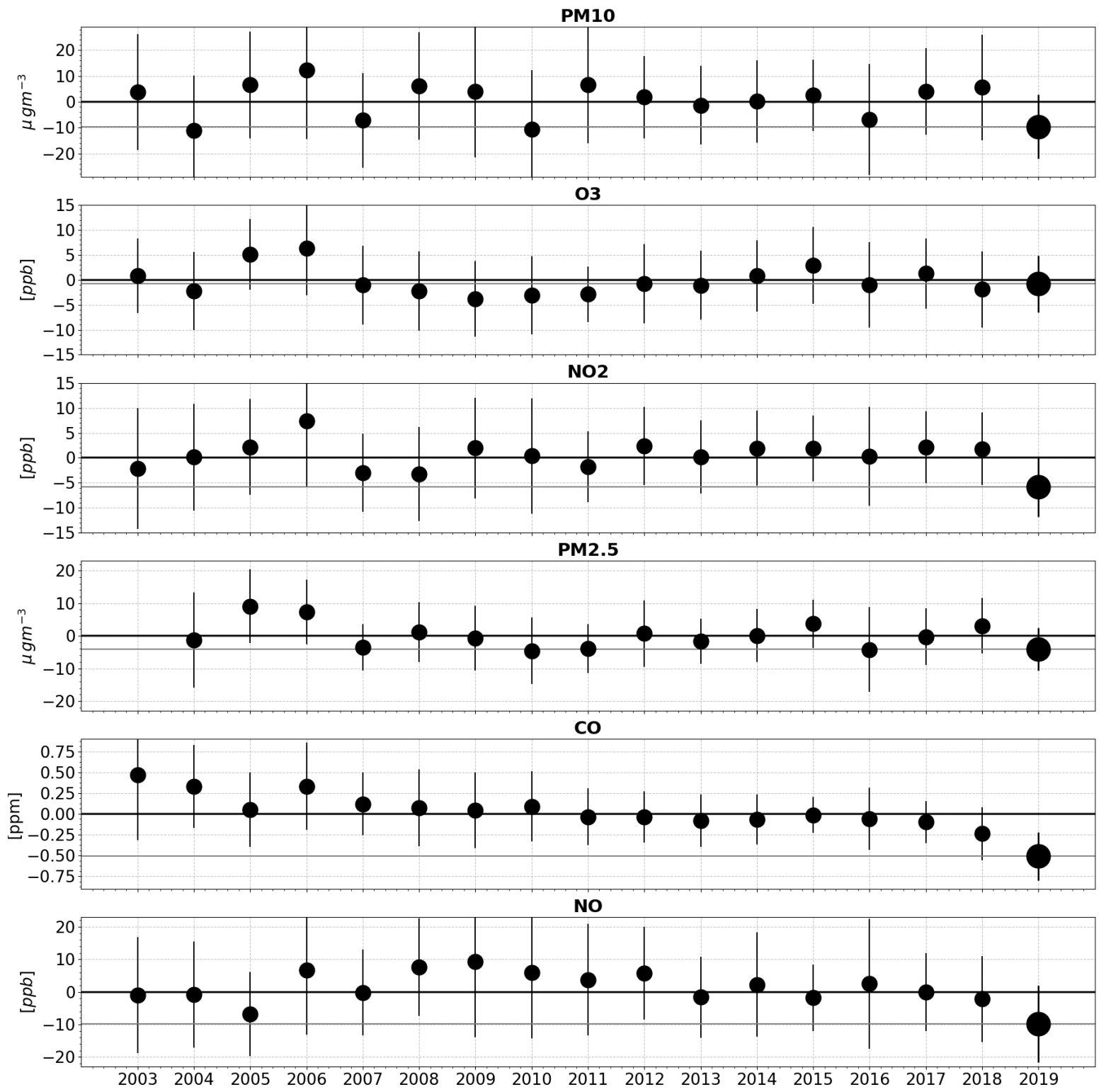

Figure 5: Yearly mean anomalies (dot) and standard deviation (lines) (see text). The larger dot highlights the anomalies during the fuel shortage. 

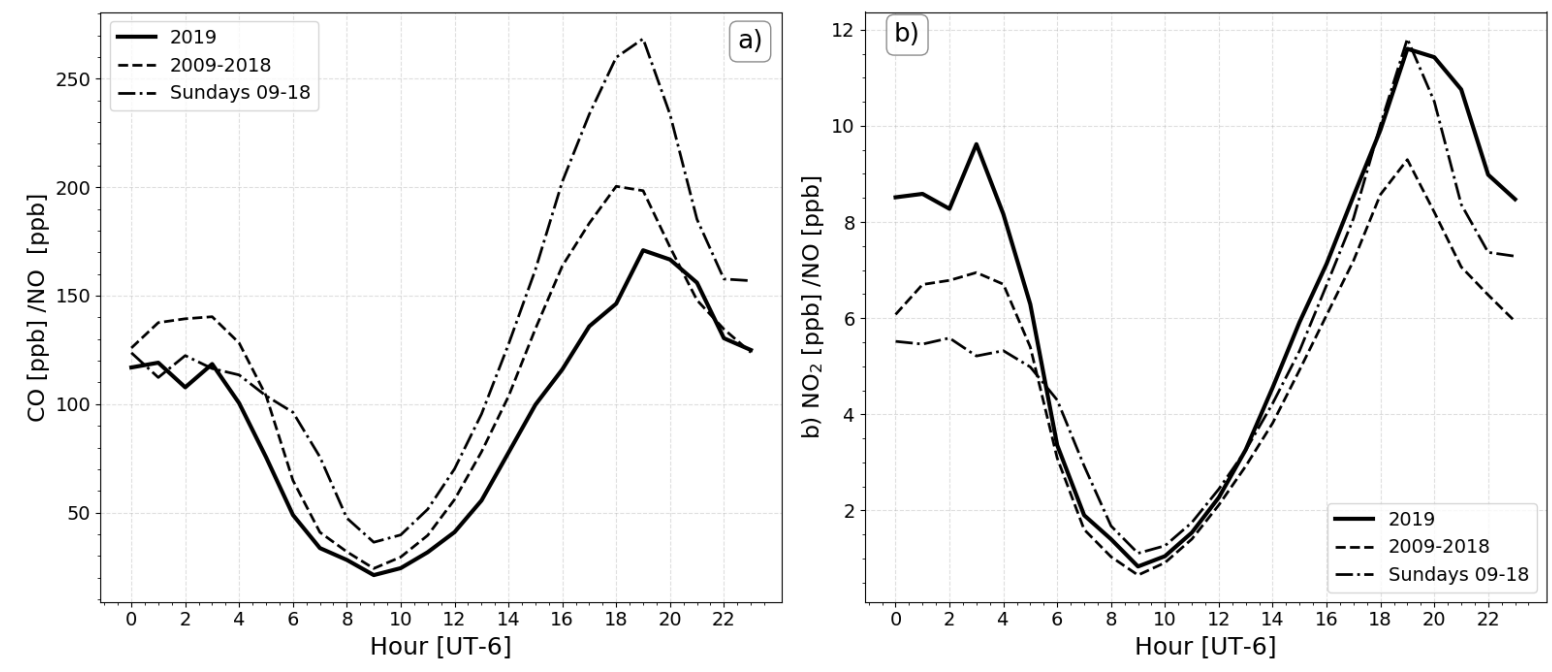

Figure 6: Hourly-mean cycle of a) $\mathrm{CO} / \mathrm{NO}$ and b) $\mathrm{NO}_{2} / \mathrm{NO}$ ratios in the period Jan. 8-26 for 2019, 2009-2018 and Sundays-only 2009-2018 as indicated in the legend. 

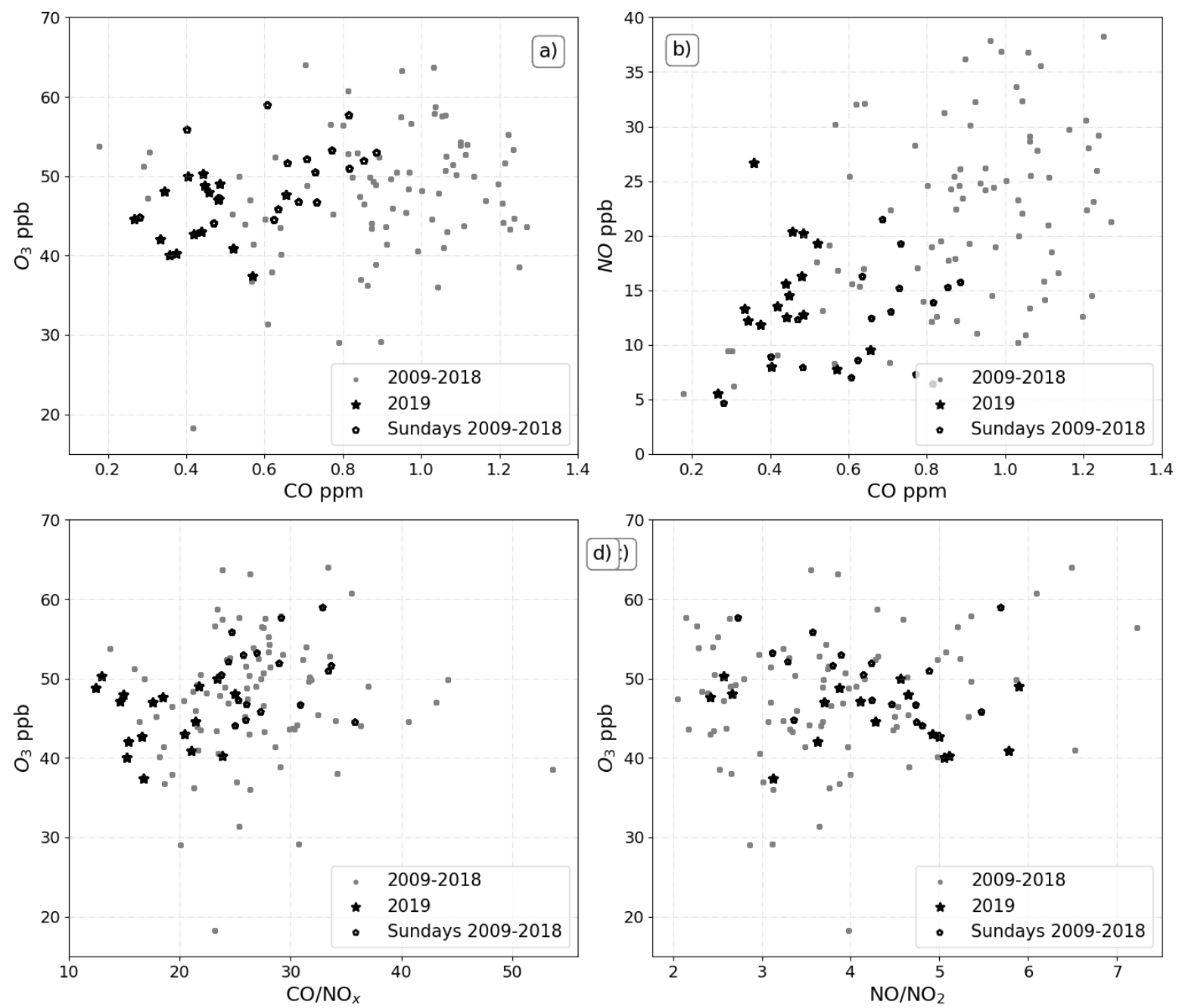

Figure 7: Scatter of daytime-mean station values of a) $C O-O_{3}$, b) $C O-N O$, c) $C O / N O_{x}-O_{3}$ and d) $\mathrm{NO} / \mathrm{NO}_{2}-\mathrm{O}_{3}$. Ratios are shown in all cases in the Jan. 8-26 window for all days in 2009-2018, Sundays-only in the same period and all days during the fuel shortage in 2019. 

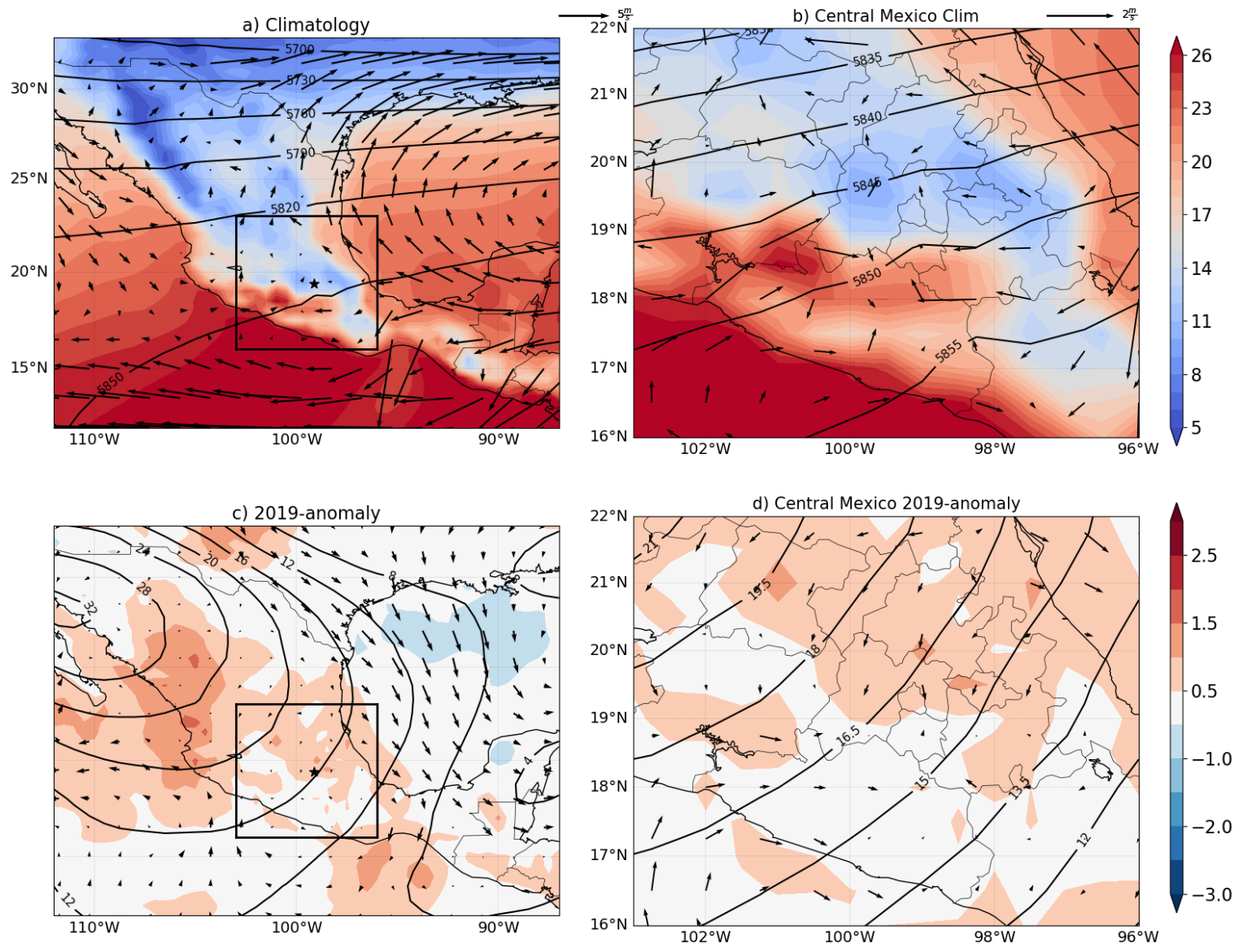

Figure 8: a) January climatological surface temperature (color-contours), GPH [m] at the 500-hPa level and surface wind speed (vectors). b) as in (a) but in the smaller domain of central Mexico. c) and d) are the anomalies of 2019 from (a) and (b), respectively. 

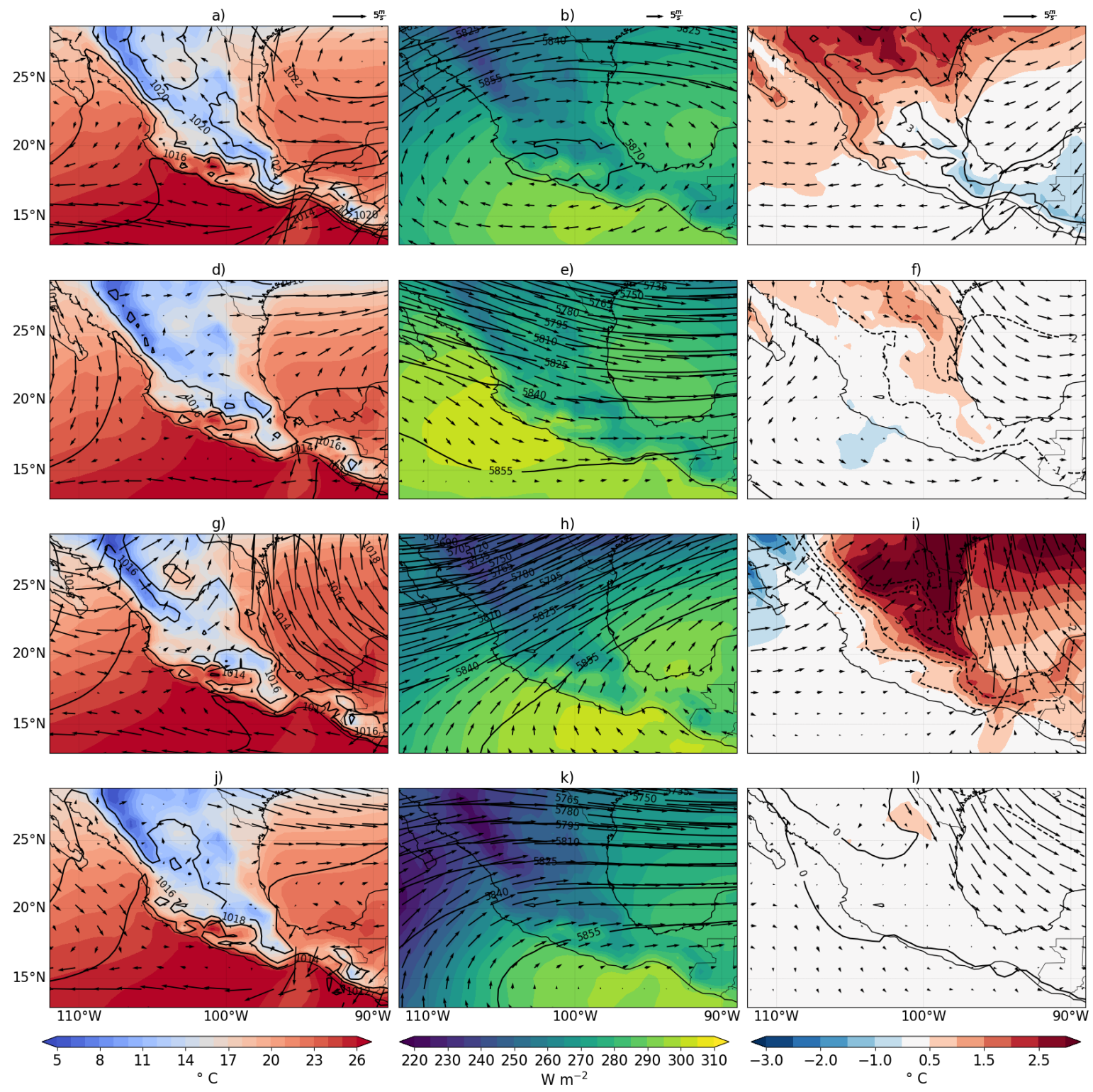

Figure 9: Composites of (left column) surface temperature (color contours), mslp (solid contours in hPa) and wind vectors at $850 \mathrm{hPa}$, (middle column) OLR (color contours), GPH (solid contours in $\mathrm{m}$ ) and wind vectors at 500-hPa. The column on the right hand side shows the anomalies of the left column from the long-term mean (fields and scales are as in the left column). The rows show positive PC1, PC2 and PC3 and negative $\mathrm{PC} 4$ events in descending order. 

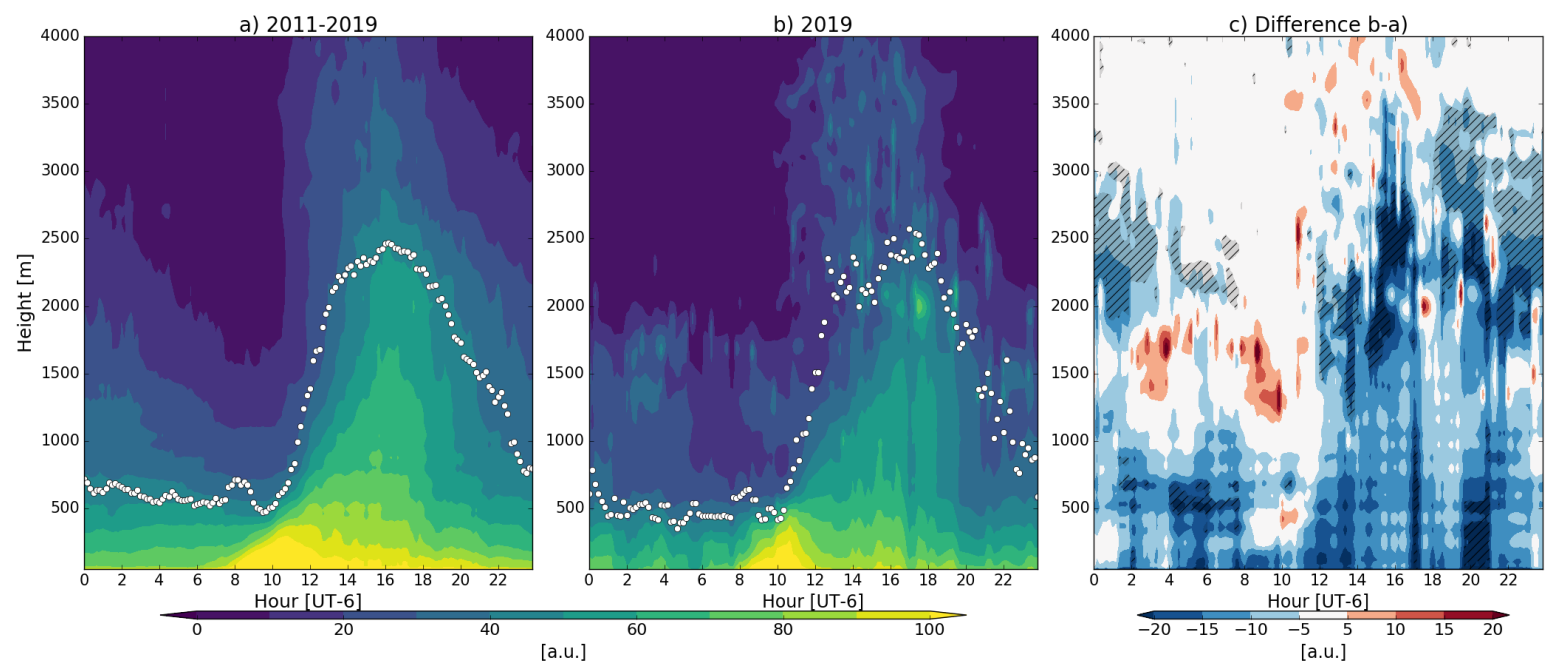

Figure 10: Backscattering composite profiles during January 8-26 from a) 2011-2019, b) only 2019 and c) the difference between b) and a); all panels are in arbitrary units [a.u.] of backscattering. The white dots on a,b) represent the mean MLH for each period. Hatching in panel c) represents values statistically significant to the $99 \%$ confidence level using a two-sided t-test. 

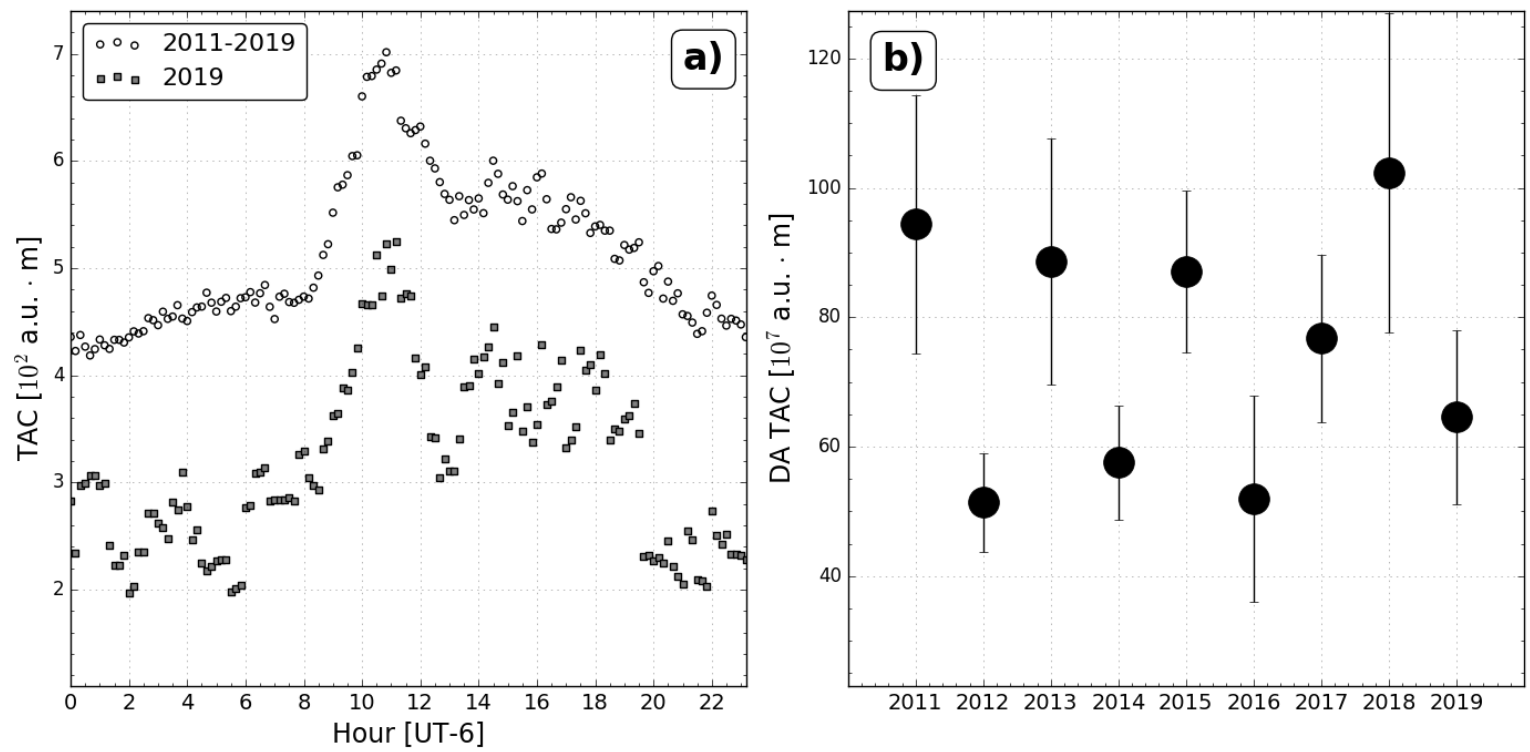

Figure 11: a) Total Aerosol content (TAC) mean daily-cycle and b) mean daily accumulated total aerosol content (DA TAC) per year during the period of the fuel shortage (Jan 8-26). 


\section{References}

Anderson, J. O., Thundiyil, J. G. and Stolbach, A. (2012), 'Clearing the air: a review of the effects of particulate matter air pollution on human health', Journal of Medical Toxicology $\mathbf{8}(2), 166-175$

Angulo, S. (2019), 'Mexico fuel shortage worries industry as lines in capital grow', Reuters .

URL: https://www.reuters.com/article/us-mexico-oil-theft/mexico-fuel-shortage-worriesindustry-as-lines-in-capital-grow-idUSKCN1P32G8

Baklanov, A., Molina, L. T. and Gauss, M. (2016), 'Megacities, air quality and climate', Atmospheric Environment 126, 235-249.

Barrett, B. S., Raga, G. B., Retama, A. and Leonard, C. (2019), 'A multi-scale analysis of the tropospheric and stratospheric mechanisms leading to the March 2016 extreme surface ozone event in Mexico City', Journal of Geophysical Research: Atmospheres .

Bell, M. L. and Davis, D. L. (2001), 'Reassessment of the lethal London fog of 1952: novel indicators of acute and chronic consequences of acute exposure to air pollution.', Environmental health perspectives 109(suppl 3), 389-394.

Bell, M. L., Davis, D. L., Gouveia, N., Borja-Aburto, V. H. and Cifuentes, L. A. (2006), 'The avoidable health effects of air pollution in three latin american cities: Santiago, sao paulo, and mexico city', Environmental research 100(3), 431-440.

Butt, E., Turnock, S., Rigby, R., Reddington, C., Yoshioka, M., Johnson, J., Regayre, L., Pringle, K., Mann, G. and Spracklen, D. (2017), 'Global and regional trends in particulate air pollution and attributable health burden over the past 50 years', Environmental Research Letters 12(10), 104017.

C3S (2017), 'ERA5: Fifth generation of ECMWF atmospheric reanalyses of the global climate.', Copernicus Climate Change Service Climate Data Store (CDS) . date of access: 18 March 2019, https://cds.climate.copernicus.eu/cdsapp\#!/home.

Davis, L. W. (2008), 'The effect of driving restrictions on air quality in Mexico City', Journal of Political Economy 116(1), 38-81.

Davis, L. W. (2017), 'Saturday driving restrictions fail to improve air quality in Mexico city', Scientific reports $\mathbf{7}, 41652$. 
de Foy, B., Caetano, E., Magana, V., Zitácuaro, A., Cárdenas, B., Retama, A., Ramos, R., Molina, L. and Molina, M. (2005), 'Mexico city basin wind circulation during the mcma-2003 field campaign', Atmospheric Chemistry and Physics Discussions 5(3), 2503-2558.

de Foy, B., Fast, J. D., Paech, S. J., Phillips, D., Walters, J. T., Coulter, R. L., Martin, T. J., Pekour, M. S., Shaw, W. J., Kastendeuch, P. P., Marley, N. A., Retama, A. and Molina, L. T. (2008), 'Basin-scale wind transport during the milagro field campaign and comparison to climatology using cluster analysis', Atmospheric Chemistry and Physics 8(5), 1209-1224.

Doran, J. C., Abbott, S., Archuleta, J., Bian, X., Chow, J., Coulter, R. L., de Wekker, S. F. J., Edgerton, S., Elliott, S., Fernandez, A., Fast, J. D., Hubbe, J. M., King, C., Langley, D., Leach, J., Lee, J. T., Martin, T. J., Martinez, D., Martinez, J. L., Mercado, G., Mora, V., Mulhearn, M., Pena, J. L., Petty, R., Porch, W., Russell, C., Salas, R., Shannon, J. D., Shaw, W. J., Sosa, G., Tellier, L., Templeman, B., Watson, J. G., White, R., Whiteman, C. D. and Wolfe, D. (1998), 'The IMADA-AVER boundary layer experiment in the Mexico City area', Bulletin of the American Meteorological Society 79(11), 2497-2508.

Gallego, F., Montero, J.-P. and Salas, C. (2013), 'The effect of transport policies on car use: Evidence from Latin American cities', Journal of Public Economics 107, 47-62.

García-Franco, J., Stremme, W., Bezanilla, A., Ruiz-Angulo, A. and Grutter, M. (2018), 'Variability of the mixed-layer height over Mexico City', Boundary-layer meteorology 167(3), 493507.

Gelaro, R., McCarty, W., Suárez, M. J., Todling, R., Molod, A., Takacs, L., Randles, C. A., Darmenov, A., Bosilovich, M. G., Reichle, R., Wargan, K., Coy, L., Cullather, R., Draper, C., Akella, S., Buchard, V., Conaty, A., da Silva, A. M., Gu, W., Kim, G.-K., Koster, R., Lucchesi, R., Merkova, D., Nielsen, J. E., Partyka, G., Pawson, S., Putman, W., Rienecker, M., Schubert, S. D., Sienkiewicz, M. and Zhao, B. (2017), 'The modern-era retrospective analysis for research and applications, version 2 (merra-2)', Journal of Climate 30, 54195454 .

URL: https://doi.org/10.1175/JCLI-D-16-0758.1

Guerra, E. and Millard-Ball, A. (2017), 'Getting around a license-plate ban: Behavioural responses to Mexico City's driving restriction', Transportation Research Part D: Transport and Environment 55, 113-126. 
Hidalgo, D. and Huizenga, C. (2013), 'Implementation of sustainable urban transport in latin america', Research in transportation economics 40, 66-77.

Holgate, S. T. (2017), 'Every breath we take: the lifelong impact of air pollution-a call for action', Clinical Medicine 17(1), 8-12.

Jauregui, E. (1988), 'Local wind and air pollution interaction in the Mexico basin', Atmósfera $1(3)$.

McDonnell, P. J. (2019), 'Gas shortages: A self-inflicted crisis by Mexico's new president?', Los Angeles Times .

URL: $\quad$ https://www.latimes.com/world/mexico-americas/la-fg-mexico-fuel-20190112story.html

Molina, L. and Molina, M. J. (2002), Air Quality in the Mexico Megacity: An Integrated Assessment, Vol. 2, Springer Science \& Business Media.

Molina, L. T., Madronich, S., Gaffney, J. S., Apel, E., de Foy, B., Fast, J., Ferrare, R., Herndon, S., Jimenez, J. L., Lamb, B., Osornio-Vargas, A. R., Russell, P., Schauer, J. J., Stevens, P. S., Volkamer, R. and Zavala, M. (2010), 'An overview of the MILAGRO 2006 campaign: Mexico city emissions and their transport and transformation', Atmospheric Chemistry and Physics 10(18), 8697-8760.

Molina, L. T., Velasco, E., Retama, A. and Zavala, M. (2019), 'Experience from integrated air quality management in the mexico city metropolitan area and singapore', Atmosphere 10, 512 .

Münkel, C., Eresmaa, N., Räsänen, J. and Karppinen, A. (2007), 'Retrieval of mixing height and dust concentration with lidar ceilometer', Boundary-layer meteorology 124(1), 117-128.

Oliva, P. (2015), 'Environmental regulations and corruption: Automobile emissions in Mexico City', Journal of Political Economy 123(3), 686-724.

Pozo, D., Marín, J. C., Raga, G. B., Arévalo, J., Baumgardner, D., Córdova, A. M. and Mora, J. (2019), 'Synoptic and local circulations associated with events of high particulate pollution in valparaiso, chile', Atmospheric environment 196, 164-178. 
Retama, A., Baumgardner, D., Raga, G., McMeeking, G. and Walker, J. (2015), 'Seasonal and diurnal trends in black carbon properties and co-pollutants in Mexico City', Atmospheric Chemistry and Physics 15(16), 9693-9709.

Rodríguez, S., Huerta, G. and Reyes, H. (2016), 'A study of trends for mexico city ozone extremes: 2001-2014', Atmósfera 29(2), 107-120.

Seastrand, S., Serra, Y., Castro, C. and Ritchie, E. (2015), 'The dominant synoptic-scale modes of north american monsoon precipitation', International Journal of Climatology 35(8), 20192032 .

SEDEMA-CDMX (2018a), 'Calidad del aire en la Ciudad de México, informe 2017', Secretaría del Medio Ambiente de la Ciudad de México Dirección General de Gestión de la Calidad del Aire, Dirección de Monitoreo Atmosférico. Ciudad de México. .

SEDEMA-CDMX (2018b), 'Inventario de Emisiones de la Ciudad de México 2016: Contaminantes criterio, tóxicos y compuestos de efecto invernadero.', Secretaría del Medio Ambiente de la Ciudad de México. Dirección General de Gestión de la Calidad del Aire, Dirección de Programas de Calidad del Aire e Inventario de Emisiones. .

Seinfeld, J. H. and Pandis, S. N. (2016), Atmospheric chemistry and physics: from air pollution to climate change, John Wiley \& Sons.

Specia, M. (2019), 'Long lines and guarded fuel: Mexico's gas crisis, explained', The New York Times .

URL: https://www.nytimes.com/2019/01/11/world/americas/mexico-gas-crisis.html

Stephens, S., Madronich, S., Wu, F., Olson, J., Ramos, R., Retama, A. and Munoz, R. (2008), 'Weekly patterns of México City's surface concentrations of CO, NO x, PM 10 and O 3 during 1986-2007', Atmospheric Chemistry and Physics 8(17), 5313-5325.

Velasco, E. and Retama, A. (2017), 'Ozone's threat hits back Mexico City', Sustainable Cities and Society 31, 260-263.

Whiteman, C., Zhong, S., Bian, X., Fast, J. and Doran, J. (2000), 'Boundary layer evolution and regional-scale diurnal circulations over the and Mexican plateau', Journal of Geophysical Research: Atmospheres 105(D8), 10081-10102. 
690 WHO, W. H. O. (2016), World health statistics 2016: monitoring health for the SDGs sustain${ }_{691}$ able development goals, World Health Organization.

${ }_{692}$ WHO, W. H. O. (2019), 'Ambient (outdoor) air quality and health'.

${ }_{693} \quad$ URL: $\quad$ https://www.who.int/en/news-room/fact-sheets/detail/ambient-(outdoor)-air$694 \quad$ quality-and-health

695 Wilks, D. S. (2011), Statistical methods in the atmospheric sciences, Vol. 100, Academic press.

${ }_{696}$ Zhou, C., Wei, G., Xiang, J., Zhang, K., Li, C. and Zhang, J. (2018), 'Effects of synoptic 697 circulation patterns on air quality in nanjing and its surrounding areas during 2013-2015', $698 \quad$ Atmospheric Pollution Research 9(4), 723-734. 